OPEN ACCESS

Edited by:

Cristina Panti,

University of Siena, Italy

Reviewed by:

Elias Fakiris,

University of Patras, Greece

Siu Gin Cheung,

City University of Hong Kong,

Hong Kong

Peter Randerson,

Cardiff University, United Kingdom

*Correspondence:

Danilo Balthazar-Silva

danilo.silva@docente.unip.br;

danilobalthazar@gmail.com

Specialty section:

This article was submitted to

Toxicology, Pollution and the

Environment

a section of the journal

Frontiers in Environmental Science

Received: 07 May 2020

Accepted: 07 July 2020

Published: 06 August 2020

Citation:

Balthazar-Silva $D$, Turra $A$, Moreira FT, Camargo RM, Oliveira AL, Barbosa L and Gorman D (2020) Rainfall and Tidal Cycle Regulate Seasonal Inputs of Microplastic

Pellets to Sandy Beaches.

Front. Environ. Sci. 8:123

doi: 10.3389/fenvs.2020.00123

\section{Rainfall and Tidal Cycle Regulate Seasonal Inputs of Microplastic Pellets to Sandy Beaches}

\author{
Danilo Balthazar-Silva ${ }^{1,2 *}$, Alexander Turra ${ }^{2}$, Fabiana Tavares Moreira ${ }^{2}$, \\ Rita Monteiro Camargo' ${ }^{2}$, Andrea Lima Oliveira ${ }^{2}$, Lucas Barbosa ${ }^{2}$ and Daniel Gorman ${ }^{2,3}$
}

1 Instituto de Ciências da Saúde, Universidade Paulista, Campus Jundiaí, São Paulo, Brazil, ${ }^{2}$ Laboratório de Manejo, Ecologia e Conservação Marinha, Instituto Oceanográfico, USP, São Paulo, Brazil, ${ }^{3}$ Commonwealth Scientific and Industrial Research Organization, Oceans and Atmosphere, Canberra, ACT, Australia

Microplastic contamination of coastal environments is a global problem and pellets used in industrial processes are a persistent and worldwide form of microplastic pollution. Regions that host port and petrochemical facilities are well known sources of plastic pellets to local and adjacent coastal areas. This study assessed pellet densities over regional and local scales to provide a greater understanding of the spatio-temporal variation in inputs to sandy beaches. Pellets were used as a proxy to undertake a multiscale assessment of the spatial (local vs. regional) and temporal (tides and weather) stranding of microplastics. Microplastic variability differed between local and regional scales. Regional variation was driven by weather (i.e., rainfall) and distance from source. Local-scale variability was driven by distance from source (along shore), tidal cycle, and beach hydrodynamics. Our results address the drivers of large spatio-temporal variability in microplastic pollution and provide useful information for monitoring programs by pointing to the need to consider variability in inputs over both regional and local scales.

Keywords: microplastic, bead, input, multi-scale variability, long-term monitoring

\section{HIGHLIGHTS}

- This study assessed plastic pellet inputs over regional and local scales.

- Microplastics variability differed between local and regional scales.

- Regional scale variation was driven by rainfall and distance from source.

- Local-scale variability depended on distance from source, tides and beach hydrodynamics.

- Understanding spatio-temporal variability of microplastic pollution can aid management.

\section{INTRODUCTION}

Contamination of coastal environments such as sandy beaches by plastic material is a major environmental problem worldwide (Browne et al., 2015; Jambeck et al., 2015). Microplastics, i.e., particles smaller than five millimeters (Andrady, 2011; Cole et al., 2011), including pellets used in industrial processes, are amongst the most abundant forms of this material even in relatively pristine areas (Turner and Holmes, 2011) and can represent up to 53\% of the overall plastic debris present in beaches (Antunes et al., 2013). 
Plastic pellets most commonly enter marine and coastal ecosystems through transportation losses in port terminals (Turner and Holmes, 2011). The persistence and biological impacts of microplastics can have severe economic and environmental effects through direct ingestion by biota, lost fisheries production and declines in tourism and recreation (Rochman et al., 2013; UNEP, 2014). Moreover, the environmental risks to humans (e.g., vector of pollutants such as PCBs and PAHs; Fisner et al., 2013a,b), demands monitoring of long-term variations in the abundance and inputs of these particles to beaches and other coastal and marine habitats.

The spatial variability in the distribution of beach litter is often related to season and site-specific factors. River supplies (Asensio-Montesinos et al., 2019) as well as hydrometeorological features (Cordova and Nurhati, 2019) generate seasonal variability in beach litter. This varibility in beach litter is also related to factors such as the proximity to densely populated areas (Browne et al., 2011; Ryan et al., 2018), river-mouth (Williams et al., 2016) and hydrodynamics (Williams et al., 2017). Similar factors are related to the spatial variability of plastic pellets within coastal ecosystems.

Recent works have demonstrated the often profound spatial variability in the distribution and accumulation of plastic pellets within coastal and marine habitats; a reality that constitutes a major conundrum to the development of assessment and monitoring programs (Turra et al., 2014; Moreira et al., 2016a,b; Fisner et al., 2017). At a broader or regional scale, catchment characteristics (i.e., proximity to sources and local weather) as well as oceanographic currents are likely to influence the stranding of particles in certain areas (Browne et al., 2011; Browne, 2015; Ryan et al., 2018). The occurrence of seasonal climatic features (e.g., wind and rainfall) can also interact with the relative loads stored in catchments to result in pulsed inputs to estuarine and coastal environments (Rech et al., 2014; Krelling et al., 2017; Gorman et al., 2020 in review).

At a local-scale (i.e., individual beaches) pellets can accumulate in zones spanning the shoreline to the backshore, the coastal dunes (often associated with strandlines; Moreira et al., 2016b) and throughout the sediment column to depths of up to $2 \mathrm{~m}$ (Turra et al., 2014). In addition, tidal cycles interfere with the dispersal of microplastics from estuaries to open waters, given that greater amounts of particles leave these environments during spring tides (Sadri and Thompson, 2014). Further, plastic pellet distribution might also be spatially variable in the along shore direction of sandy beaches (Bowman et al., 1998) as a result of hydrodynamics (Andrady, 2015; Thompson, 2015) and relative proximity to sources (Karapanagioti and Klontza, 2008; Turner and Holmes, 2011). These environmental processes are responsible for variations in the stranding rates (input) and accumulation (standing stock) of plastic pellets in sandy beaches (Turra et al., 2014; Moreira et al., 2016a,b).

A key requirement to understanding processes of stranding and accumulation of plastic pellets, is knowledge of the variability in inputs over both spatial and temporal scales (Duis and Coors, 2016). In this context, we conducted a multi-scale assessment of the spatio-temporal inputs of plastic pellets to sandy beaches along the central coast of São Paulo state, Brazil. The initial aim was to assess variation in the inputs of plastic pellets driven by regional-scale characteristics such as distance from potential sources and weather. We tested the hypothesis that inputs would show variability among regional (i.e., "beaches") and temporal replicates (i.e., "months"). Having identified some of the principal drivers of variability at the regional scale (i.e., climate and rainfall) we then focused on local-scale phenomenon by testing the effects of season (i.e., the onset vs. end of the rainy season), along shore beach position (along shore) and consecutive tidal cycles. Here we tested the hypothesis that variation in plastic pellet inputs differ along the shore and over consecutive tidal cycles and season. Overall, our goal was to present useful information describing the spatio-temporal dynamics of plastic pellet contamination of sandy beaches for monitoring programs tasked with evaluating the environmental risks to the biota (Nelms et al., 2015) and to the physical environment (Antunes et al., 2013). This approach is also useful as a baseline information for monitoring programs that could evaluate the efficiency of the adoption of the "zero pellets loss" programs (in before and after impact design) (e.g. Operation Clean Sweep; Plastics \& ACC, 2017).

\section{MATERIALS AND METHODS}

We used a hierarchical sampling design to test regional and local scale variability in the input of plastic pellets to sandy beaches of the Santos region of Brazil (Figure 1). The rationale was to understand better the drivers of the often high variability observed in estimates of plastic pellet input and standing stocks (see Moreira et al., 2016a,b). The sampling focused on recently stranded pellets by the last tidal cycle, present only in the intertidal up to the last high tide mark. We began by investigating variability in the density (i.e., numbers of particles per linear meter along transects) of stranded plastic pellets at regional scale, among beaches located at different distance from known sources of plastic pellet inputs (Pereira, 2014) (the port of Santos, Figure 1C). In this regional scale, we evaluated the interference of the rainy season on the dispersion and occurrence of plastic pellets, so we developed a novel sampling design to accomplish surveying in the dry season (April, May, June, July, August, and September) and in the rainy season (October, November, December, January, February, and March). We then focused on the influence of local-scale phenomena including, alongbeach distribution, tidal cycles (semidiurnal), and hydrographic processes within a heavily impacted and relatively well-studied beach arc (Figure 1C; Santos Bay; Turra et al., 2014).

\section{Regional-Scale}

At regional scale, the spatial and temporal variability of plastic pellet inputs was evaluated at four beaches along the central coastline of São Paulo (Figure 1B) which are located at different distances from a known major source (i.e., the port of Santos) (Fisner et al., 2013a,b; Taniguchi et al., 2016). The selected beaches (ranked by distance from Santos) included Canal cinco, Ocian, Iporanga and Itaguaré, all of which can be characterized as dissipative/intermediate morphodynamic with a NE-SW 


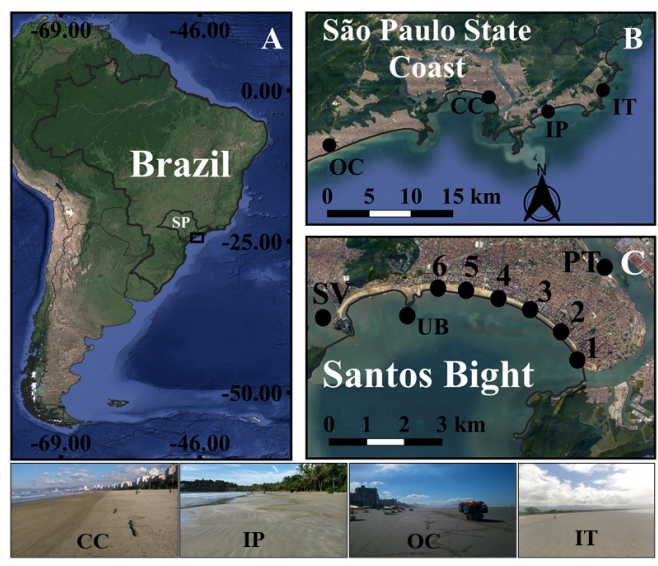

FIGURE 1 | Study sites included in the multi-scale assessments of spatio-temporal variation in plastic pellet pollution; (A) Brazil, showing the location of São Paulo state (SP). (B) Regional-scale study including Ocian (OC), Canal cinco (CC), and Iporanga (IP) and Itaguaré (IP). (C) Small scale replicates within Santos Bight, dots with number represent the sampling locations (1, 2, 3, 4, 5, 6), PT indicates the location of Santos Port Terminal, UB is Urubuqueçaba Island and SV is São Vicente Channel.

orientation. Although differing in their catchment characteristics and coastal geomorphology, these beaches experience similar hydrodynamic and morphodynamics processes. Sampling was done between February 2014 and February 2015 to capture rainy and dry seasons.

\section{Local-Scale}

Having investigated variability in pellet inputs at a regional scale, we then focused our attention on processes operating at localscale by assessing the influence of along shore position, tidal cycle and hydrodynamic process within Santos Bay itself (Figure 1C). The study area for this component incorporated a $7 \mathrm{~km}$ stretch of exposed sandy beach with an east-west orientation sheltered and a degree of protection at the western end (i.e., due to the blocking effect of Urubuqueçaba Island; Elliff et al., 2013). The area receives estuarine waters discharged both from the Santos Channel in east and the São Vicente Channel in the west (Gregorio, 2009). The coastline also receives urban and industrial runoff via seven drainage channels that are interspersed along the beach approximately every $1 \mathrm{~km}$ (Italiani, 2014). Sampling was done in November 2014 and again in March of 2015 to capture seasonal variation; representing the beginning and end of the wetseason in Brazil, respectively. Within these seasonal replicates, sampling was done during the spring tides, at six sampling points along shore (at increasing distances from the Santos channel, a potential source of pellets).

\section{Sampling Approach}

Sampling at both scales was done during low tide (between 0 and $0.5 \mathrm{~m}$ ), using five $2-\mathrm{m}$ wide transects oriented in a crossshore direction (up/down shore). The across-shore extension of transects varied according to beach morphology and the amplitude of the tides (Moreira et al., 2016a). Each transect was pre-prepared by cleaning all plastic pellets along marked transects prior to sampling. This had the effect of creating a clean surface, so that subsequent sampling would only collect newly stranded pellets within the last tidal cycle. The sampling procedure involved gathering all stranded pellets in the low tides prior and after to the tidal cycle by scraping the surface of the sediment with a squeegee from the water line to the high strandline. Processing of collected particles involved washing the mix of sediment and the other material through a $0.1 \mathrm{~mm}$ sieve. Isolated pellets were packaged on-site and transported to the laboratory for counting. At the Regional-scale, sampling was repeated during different sampling periods (dry and rainy seasons) and spanned a full year (i.e., February 2014 and February 2015). For the local scale, sampling was done in November 2014 and March 2015, over three subsequent low tides at the same time at all sites by different teams. Transects sampled in each site were randomly established at the beginning of each season and were resampled during the three consecutive low tides.

\section{Data Analysis}

Variability in plastic pellet densities at both scales was assessed using analysis of variance (ANOVA). At the regional scale, data were analyzed using two-way ANOVA, considering the factors "weather," with two levels, representing the sampling conducted in dry and rainy seasons, and replicate beaches, with four levels, representing catchments of differing characteristics and distance from source (Santos port terminal). Data were checked for heterogeneity of variance using Cochran's test and $\ln$ $(\mathrm{x}+1)$ transformed where necessary. The significant differences were a posteriori evaluated with the Student-Newman-Keuls test (SNK) (Underwood, 1997). At the local scale, data were analyzed using three-way repeated measures ANOVA, considering the factors "zones," with six levels, representing along shore beach position (along shore), "cycles", with three levels, representing three consecutive low tide cycles and "season," with two levels representing the onset and the end of the rainy season (November and March respectively). The significant differences were evaluated with Bonferroni test (Quinn and Keough, 2002).

\section{RESULTS}

\section{Regional-Scale}

At the regional scale, there was substantial variability in the density of pellets across the year and among beaches (Figure 2A), with strong peaks observed for Canal cinco between November 2014 and February 2015 (i.e., coinciding with the rainy season) and Iporanga during April and August 2014. In general, the lowest densities of plastic pellets were observed during dry season, while the higher estimates were observed during wet season. There was also an overall trend of decreasing inputs with increasing distance from the Port of Santos (Figure 2B). When comparing the density of pellets between dry and wet seasons, sites demonstrated different patterns (Figure $\mathbf{3}$ and Table 1, "Weather $\times$ Beach" interaction term) with those closer to the Port of Santos showing the greatest difference between dry and rainy season. 

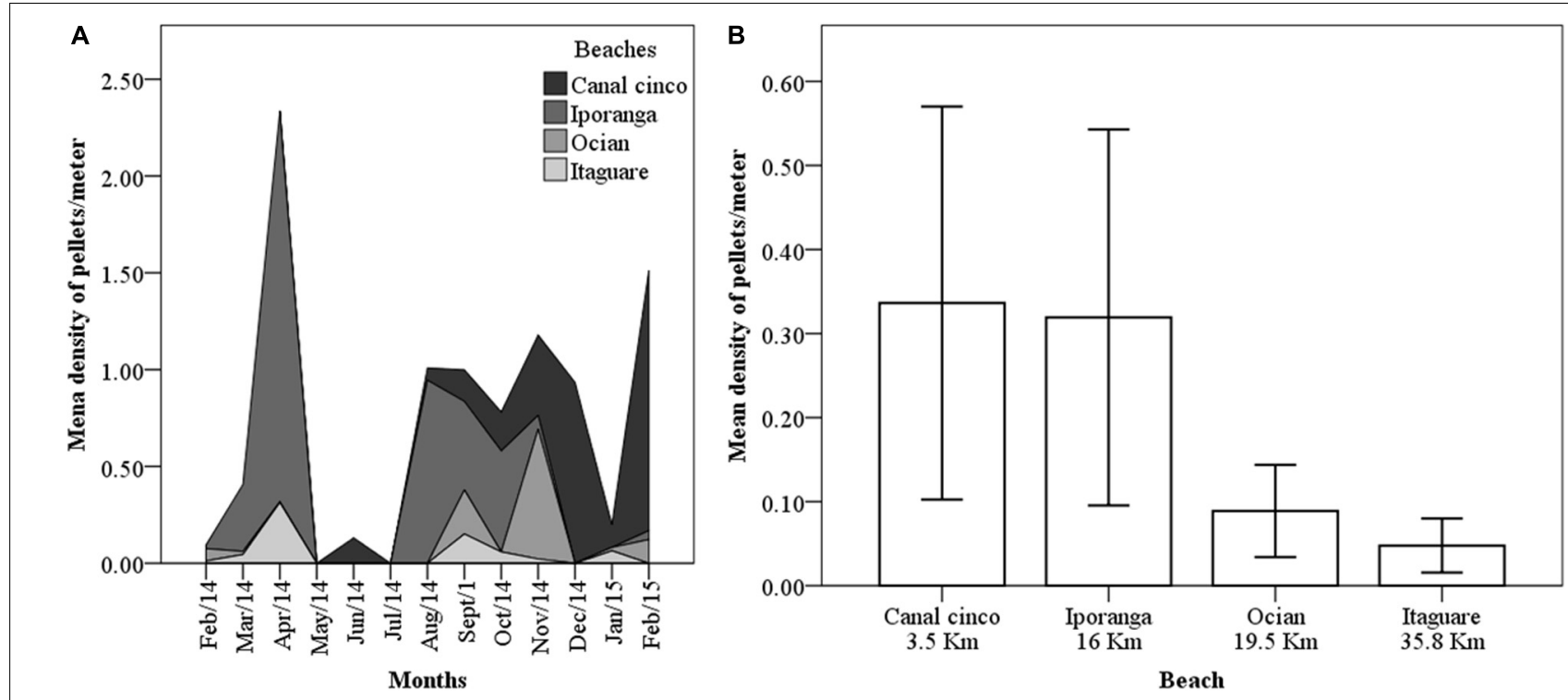

FIGURE 2 | Estimates of plastic pellet inputs to replicate beaches along the coastline of São Paulo state; (A) over 1 year, and (B) with $x$-axis reflecting the distance of each beach from the Port of Santos. The bars represent mean ( \pm SE) for sampling sites for each replicate beach.

\section{Local-Scale}

Analysis of plastic pellet density revealed a smaller quantity of pellets prior to the rainy season (Figures 4A,B). Further, the analysis of the local scale revealed a significant variation according to the sampling season and an interaction between tidal cycles and the along-shore location. An interesting observation was that there was no interaction between season

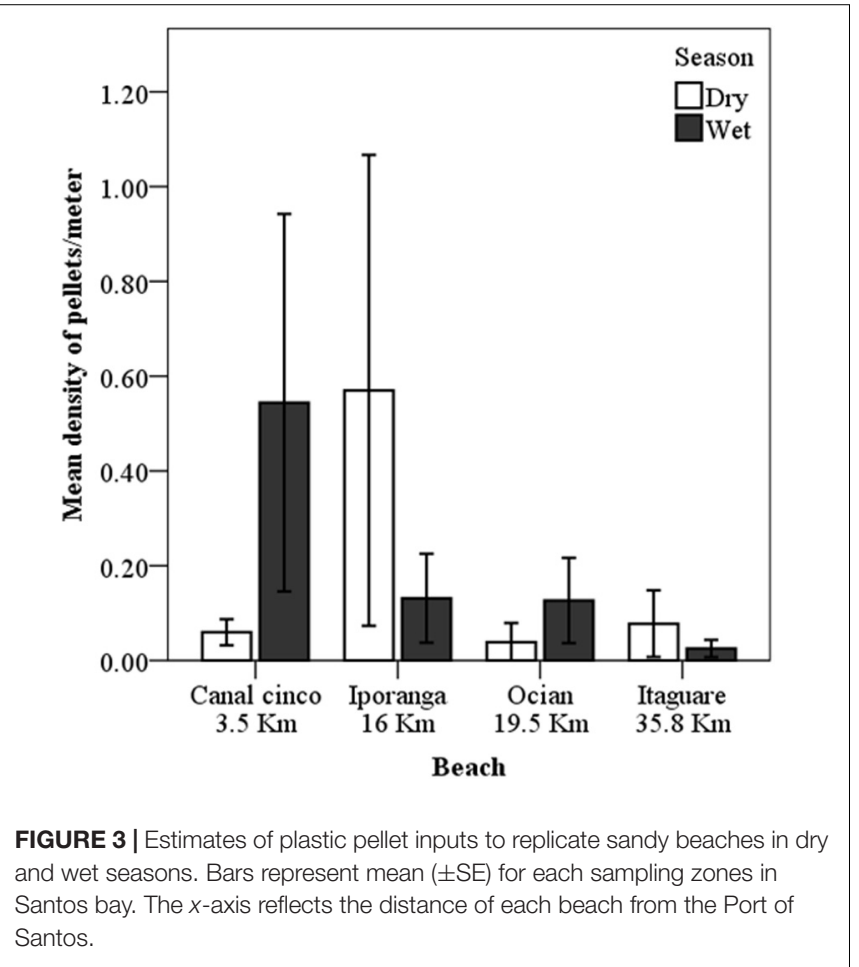

and zones or cycles, suggesting that these patterns were relatively consistent (Figure 4 and Table 2). The significant interaction between "zones and cycles" suggested that the variability in pellet density over consecutive cycles is different in the along-shore beach position. Indeed, the pairwise test revealed significant differences among cycles.

\section{DISCUSSION}

The aim of this study was to investigate the drivers of spatiotemporal variability in microplastic pellet inputs to sandy

TABLE 1 | Two-way ANOVA comparing plastic pellet inputs to four regional beaches along the coast of São Paulo state during different weather conditions (dry vs. wet).

\begin{tabular}{lcccc}
\hline Source & $\boldsymbol{d f}$ & MS & $\boldsymbol{F}$ & $\boldsymbol{P}$ \\
\hline Weather & 1 & 42.13 & 52.43 & $<0.001$ \\
Beach & 3 & 23.6 & 29.36 & $<0.001$ \\
Weather $\times$ beach & 3 & 5.37 & 6.68 & $<0.001$ \\
Error & 182 & 0.804 & - & - \\
Total & 190 & - & - & - \\
\hline \multicolumn{5}{c}{ SNK-test results } \\
\hline
\end{tabular}

Dry:

Wet:

Canal cinco $>$ Iporanga

Canal cinco $>$ Iporanga

Canal cinco $>$ Itaguaré

Canal cinco $>$ Itaguaré

Canal cinco $=$ Ocian

Canal cinco $>$ Ocian

Iporanga $=$ Itaguaré $=$ Ocian
Iporanga $>$ Itaguaré

Iporanga $=$ Ocian

Itaguaré = Ocian 

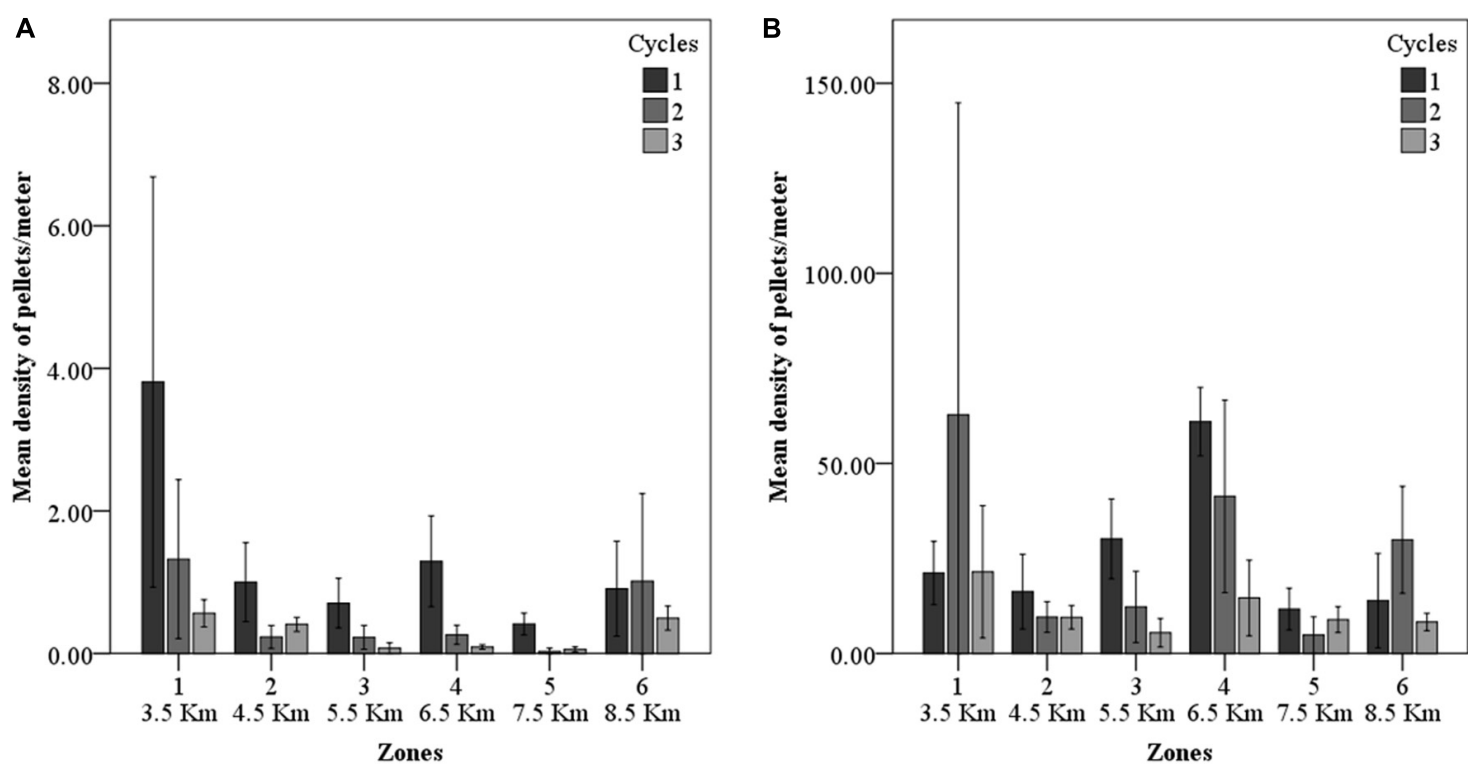

FIGURE 4 | Estimates of plastic pellet inputs to sandy beaches at the "local-scale" during; (A) the onset of the rainy season (November), and (B) at the end of the rainy season (March). Data are grouped by zones (with increasing distance from the Santos channel in $x$-axis) and by consecutive tidal cycle (following mean high tide of spring). The bars represent mean $( \pm S E)$ for each sampling zones.

beaches. We assessed the influence of regional characteristics (i.e., rainfall and distance from known source) and local-scale phenomena (i.e., along shore zonation and tides) on variability in the density of plastic pellets stranded on sandy beaches. Our results suggest that factors operating at both scales can have strong and predictable consequences for patterns of pellet deposition and might need to be considered when designing and conducting monitoring programs that are often hampered by the large variability in standing stocks of microplastic contamination (Moreira et al., 2016a).

At a regional scale, inputs of plastic pellets varied considerably across an entire year and showed significant correlation with the geographical (distance) and local weather conditions (rainfall) of various beaches. Overall, Canal cinco showed the greatest inputs, which is not surprising given its proximity to the Port of Santos (i.e., a known source) and its position within the Santos Bay. Our

TABLE 2 | Three-way repeated measures ANOVA comparing plastic pellet inputs across different local-scale phenomena; including sampling season (onset vs. end of the rainy season), beach zone (along shore beach position) and tidal cycle (three consecutive low tides).

\begin{tabular}{lrrrrr}
\hline Source & SS & $\boldsymbol{d} \boldsymbol{f}$ & MS & $\boldsymbol{F}$ & $\boldsymbol{P}$ \\
\hline Season & 42.57 & 1.00 & 42.57 & 48.87 & 0.00 \\
Zones & 2.91 & 2.16 & 1.35 & 3.94 & 0.06 \\
Cycles & 2.12 & 2.00 & 1.06 & 51.70 & 0.00 \\
Season $\times$ zones & 1.06 & 2.85 & 0.37 & 2.72 & 0.10 \\
Season $\times$ cycles & 0.24 & 1.34 & 0.18 & 3.42 & 0.12 \\
Zones $\times$ cycles & 1.83 & 2.39 & 0.76 & 5.22 & 0.03 \\
Season $\times$ zones $\times$ cycles & 1.21 & 2.97 & 0.41 & 3.13 & 0.07 \\
Pairwise comparisons on cycles: $1>2 ; 1>3 ; 2>3$ & &
\end{tabular}

results thus concur with other recent studies on the abundance of plastic litter indicating that the temporal dynamics can be influenced by the distance from industrial and urban centers (Laglbauer et al., 2014; Davis and Murphy, 2015; Gorman et al., 2019; Izar et al., 2019). Inputs declined as a function of distance, although not in a direct linear fashion, and were $\sim 15 \%$ (cf. Canal cinco) at the beach Itaguare located $\sim 38 \mathrm{~km}$ to the northeast. This pattern emphasizes the importance of coastal currents, wind and circulation patterns as factors that influence the dispersal of plastic particles (Law et al., 2014; Gorman et al., 2020 in review). The variability across relatively large spatial scales observed in the present study (tens of kilometers) indicates that long-term surveys of the plastic pellets input should consider the distance from potential sources as part of the sampling procedure.

We also demonstrate the strong influence of rainfall on the input of pellets and probably other microplastic particles to sandy beaches. In the rainy season, the rate at which pellets were stranded increased, with the highest values again observed for Canal cinco. The hydrological and sedimentary processes occurring in this beach are under the influence of strong tidal currents that originate from the Santos estuary. The currents in this location are influenced by the progressive tidal waves inside of the channel and are North-South oriented (Harari and de Camargo, 2003). It appears that the "flushing" of plastic materials accumulated within the catchment (during comparatively dry periods) out of the estuary and into coastal waters (Gorman et al., 2020 in review) results in a "pulse" of stranded pellets on adjacent beaches. Overall, our results suggest that long-term monitoring programs should consider the differences between chronic and episodic inputs as failure to account for pulsed inputs may lead to substantial errors in estimates, even among samples taken in consecutive days (also see Moreira et al., 2016a). 


\section{Local-Scale}

Having established the importance of regional-scale characteristics (specifically distance from source and rainfall) as determinants of pellet inputs to sandy beaches, we then focused on the effect of local-scale drivers that may help to explain accumulation processes at the scale of individual beaches. Recently, Moreira et al. (2016a) recommended that surveys investigating input dynamics should include small-scale spatial and temporal stratification in order to identify patterns and provide more reliable estimates. Our data show that different degrees of wave action along the beach, tidal cycles, and season (i.e., the onset vs. end of rainy season) can all contribute to the variability in plastic particle estimates.

The first thing to note were the seasonal differences in inputs, which were higher at the end of the rainy season (March) than they were at the onset (November). This is likely to reflect variation in important physical distribution mechanisms that can influence the sources and sinks of plastic particles at a localscale (Vermeiren et al., 2016). Estimates of the particle flux for microplastics in estuaries have previously shown that they are correlated to weather conditions, such as wind and rainfall (Yonkos et al., 2014), and to seasonal hydrodynamic features (Lima et al., 2015). Indeed, a recent modeling study within the Santos region has shown seasonal variation in the movement of plastic particles, where greater amounts of debris coincide with rainfall events (Gorman et al., in review). It is likely that the material released from the estuary at the onset of the rainy season, takes some time to disperse to the adjacent beaches of Santos. This time lag is another factor that should be considered when attempting to understand patterns of microplastic pollution of coastal habitats.

Local-scale variability in pellet density was also influenced by an interaction between beach zone (reflecting beach morphodynamics) and tidal cycle. At the onset of the rainy season, zones 1-5 had greater inputs in the initial tidal cycle. Contrastingly, the density of stranded pellets increased at zones 1 and 6 over the subsequent two tidal cycles. These observations are likely to be governed by seasonal differences in the depositional environment along the beach (onset vs. end of the rainy season). The volume of water exiting the channel along with the highenergy tidal events likely generate conditions that are favorable to particle deposition close to the channel (Magini et al., 2007). On the other hand, the influence of Urubuqueçaba Island on hydrodynamic features of Santos Bay generates favorable conditions of deposition in zones 4 to 6 (see Turra et al., 2014). The beach dynamics also explain the different variation of pellet inputs over consecutive tidal cycles from zone 1-6. Indeed, after three low tide cycles, inputs had declined on average from the initial pulse. This result helps to clarify the interference of physical processes on microplastics settling in the sediment column and in the promotion of differences in local spatial scales (Turra et al., 2014). Future work should consider this relationship in order to evaluate the impacts of local distribution of plastic particles on physical environmental processes (Carson et al., 2011) and to the biota (Koelmans et al., 2014).

In conclusion, we show that the large variability often observed in the density of plastic pellets (see Turra et al., 2014) can be partially explained by large variability in the input-dynamics, operating across both regional- and localscales. Geographic location (distance from potential sources), weather, tidal cycles and oceanographic processes are all likely to influence the density of plastic particles that become stranded on sandy beaches and potentially other coastal habitats. We suggest that these factors need to be incorporated into the design of the risk assessment and monitoring protocols to improve the accuracy and efficiency of estimates of microplastic contamination. Failing to incorporate (or at least report) the conditions under which sampling was conducted (e.g., before or after rain?) could lead to spurious and unreliable results that limit our ability to compare trends over time and space. Overall, while we address the considerable variation in microplastic density estimation, it is clear that more work needs to be done to fully understand the distribution patters, processes of accumulation and implications of microplastics contamination within marine and coastal habitats (e.g., Hidalgo-Ruz et al., 2012; Ivar do Sul and Costa, 2014).

\section{DATA AVAILABILITY STATEMENT}

The raw data supporting the conclusions of this article will be made available by the authors, without undue reservation.

\section{AUTHOR CONTRIBUTIONS}

DB-S is the first author, he contributed in field work, data analysis and writing. AT was DB-S advisor. FM also was DB-S advisor. RC, $\mathrm{AO}$, and LB contributed in field work. DG contributed in data analysis and writing. All authors contributed to the article and approved the submitted version.

\section{FUNDING}

This research was funded jointly by: the Coordination of Enhancement of Higher Education (CAPES) through a Ph.D. scholarship to DB-S (7641123); by the Fundação de Amparo à Pesquisa do Estado de São Paulo (FAPESP) through Young Researcher scholarships to DG (2016/26064-3 and 2018/061626); Brazilian Socioenvironmental Institute of Plastics (Plastivida); and by the National Council for Scientific and Technological Research (CNPq) to AT (301240/2006-0, 308124/2009-0, 484475/2011-8, 309697/2015-8, and 310553/2019-9). 


\section{REFERENCES}

Andrady, A. L. (2011). Microplastics in the marine environment. Mar. Pollut. Bull. 62, 1596-1605. doi: 10.1016/j.marpolbul.2011.05.030

Andrady, A. L. (2015). "Persistence of plastic litter in the oceans," in Marine Anthropogenic Litter, eds M. Bergman, L. Gutow, and M. Klages, (Berlin: Springer International Publishing), 57-72. doi: 10.1007/978-3-319-16510-3_3

Antunes, J. C., Frias, J. G. L., Micaelo, A. C., and Sobral, P. (2013). Resin pellets from beaches of the Portuguese coast and adsorbed persistent organic pollutants. Estuar. Coast. Shelf Sci. 130, 62-69. doi: 10.1016/j.ecss.2013.06.016

Asensio-Montesinos, F., Anfuso, G., Randerson, P., and Williams, A. T. (2019). Seasonal comparison of beach litter on Mediterranean coastal sites (Alicante. SE Spain). Ocean Coast. Manag. 181:104914. doi: 10.1016/j.ocecoaman.2019. 104914

Bowman, D., Manor-Samsonov, N., and Golik, A. (1998). Dynamics of litter pollution on israeli mediterranean beaches: a budgetary, litter flux approach. J. Coast. Res. 14, 418-432.

Browne, M. A. (2015). "Sources and pathways of microplastics to habitats," in Marine Anthropogenic Litter, eds M. Bergmann, L. Gutow, and M. Klages, (Berlin: Springer International Publishing), 229-244. doi: 10.1007/978-3-31916510-3_9

Browne, M. A., Crump, P., Niven, S. J., Teuten, E., Tonkin, A., Galloway, T., et al. (2011). Accumulation of microplastic on shorelines woldwide: sources and sinks. Environ. Sci. Technol. 45, 9175-9179. doi: 10.1021/es201811s

Browne, M. A., Underwood, A. J., Chapman, M. G., Williams, R., Thompson, R. C., and Franeker, J. A. V. (2015). Linking effects of anthropogenic debris to ecological impacts. Proc. R. Soc. B Biol. Sci. 282, 1-10. doi: 10.1098/rspb.2014. 2929

Carson, H. S., Colbert, S. L., Kaylor, M. J., and McDermid, K. J. (2011). Small plastic debris changes water movement and heat transfer through beach sediments. Mar. Pollut. Bull. 62, 1708-1713. doi: 10.1016/j.marpolbul.2011.05.032

Cole, M., Lindeque, P., Halsband, C., and Galloway, T. S. (2011). Microplastics as contaminants in the marine environment: a review. Mar. Pollut. Bull. 62, 2588-2597. doi: 10.1016/j.marpolbul.2011.09.025

Cordova, M. R., and Nurhati, I. S. (2019). Major sources and monthly variations in the release of land-derived marine debris from the Greater Jakarta area. Indonesia. Sci. Rep. 9, 1-8. doi: 10.1038/s41598-019-55065-2

Davis, W. III, and Murphy, A. G. (2015). Plastic in surface waters of the inside passage and beaches of the salish sea in washington state. Mar. Pollut. Bull. 97, 169-177. doi: 10.1016/j.marpolbul.2015.06.019

Duis, K., and Coors, A. (2016). Microplastics in the aquatic and terrestrial environment: sources (with a specific focus on personal care products), fate and effects. Environ. Sci. Eur. 28:2. doi: 10.1186/s12302-015-0069-y

Elliff, C. I., Motta, N. D. S., Scricco, I. M., and Barros, M. O. (2013). Classificação Morfodinâmica da Praia do Gonzaga, Santos, São Paulo, Brasil. Cad. Geociências 10, 133-138.

Fisner, M., Majer, A. P., Balthazar-Silva, D., Gorman, D., and Turra, A. (2017). Quantifying microplastic pollution on sandy beaches: the conundrum of large sample variability and spatial heterogeneity. Environ. Sci. Pollut. Res. 24, 1373213740. doi: 10.1007/s11356-017-8883-y

Fisner, M., Taniguchi, S., Majer, A. P., Bícego, M. C., and Turra, A. (2013a). Concentration and composition of polycyclic aromatic hydrocarbons (PAHs) in plastic pellets: implications for small-scale diagnostic and environmental monitoring. Mar. Pollut. Bull. 76, 349-354. doi: 10.1016/j.marpolbul.2013.09. 045

Fisner, M., Taniguchi, S., Moreira, F., Bícego, M. C., and Turra, A. (2013b). Polycyclic aromatic hydrocarbons (PAHs) in plastic pellets: variability in the concentration and composition at different sediment depths in a sandy beach. Mar. Pollut. Bull. 70, 219-226. doi: 10.1016/j.marpolbul.2013. 03.008

Gorman, D., Moreira, F. T., Turra, A., Fontenelle, F. R., Combi, T., Bícego, M. C., et al. (2019). Organic contamination of beached plastic pellets in the South Atlantic: risk assessments can benefit by considering spatial gradients. Chemosphere 223, 608-615. doi: 10.1016/j.chemosphere.2019.02.094

Gregorio, H. P. (2009). Modelagem Numérica da Dispersão da Pluma do Emissário Submarino de Santos. Ph.D. thesis, Universidade de São Paulo, São Paulo. doi: 10.11606/D.21.2009.tde-19012010-165632
Harari, J., and de Camargo, R. (2003). Numerical simulation of the tidal propagation in the coastal region of Santos (Brazil, $24^{\circ} \mathrm{S} 46^{\circ} \mathrm{W}$ ). Cont. Shelf Res. 23, 1597-1613. doi: 10.1016/S0278-4343(03)00143-2

Hidalgo-Ruz, V., Gutow, L., Thompson, R. C., and Thiel, M. (2012). Microplastics in the marine environment: a review of the methods used for identification and quantification. Environ. Sci. Technol. 46, 3060-3075. doi: 10.1021/es2031505

Italiani, D. M. (2014). Resposta Morfodinâmica à Alimentação Artificial da Ponta da Praia, Santos, SP. Thesis, University of São Paulo, Brazil.

Ivar do Sul, J. A., and Costa, M. F. (2014). The present and future of microplastic pollution in the marine environment. Environ. Pollut. 185, 352-364. doi: 10. 1016/j.envpol.2013.10.036

Izar, G. M., Morais, L. G., Pereira, C. D. S., Cesar, A., Abessa, D. M. S., and Christofoletti, R. A. (2019). Quantitative analysis of pellets on beaches of the São Paulo coast and associated non-ingested ecotoxicological effects on marine organisms. Reg. Stud. Mar. Sci. 29:100705. doi: 10.1016/j.rsma.2019.100705

Jambeck, J. R., Geyer, R., Wilcox, C., Siegler, T. R., Perryman, M., Andrady, A., et al. (2015). Plastic Waste inputs from land into the ocean. Science 347, 768-770.

Karapanagioti, H. K., and Klontza, I. (2008). Testing phenanthrene distribution properties of virgin plastic pellets and plastic eroded pellets found on Lesvos island beaches (Greece). Mar. Environ. Res. 65, 283-290. doi: 10.1016/j. marenvres.2007.11.005

Koelmans, A. A., Besseling, E., and Foekema, E. M. (2014). Leaching of plastic additives to marine organisms. Environ. Pollut. 187, 49-54. doi: 10.1016/j. envpol.2013.12.013

Krelling, A. P., Souza, M. M., Williams, A. T., and Turra, A. (2017). Transboundary movement of marine litter in an estuarine gradient: evaluating sources and sinks using hydrodynamic modelling and ground truthing estimates. Mar. Pollut. Bull. 119, 48-63. doi: 10.1016/j.marpolbul.2017.03.034

Laglbauer, B. J. L., Franco-Santos, R. M., Andreu-Cazenave, M., Brunelli, L., Papadatou, M., Palatinus, A., et al. (2014). Macrodebris and microplastics from beaches in Slovenia. Mar. Pollut. Bull. 89, 356-366. doi: 10.1016/j.marpolbul. 2014.09.036

Law, K. L., More, S. E., Goodwin, D. S., and Zettler, E. R. (2014). Distribution of surface plastic debris in the eastern paci fi c Ocean from an 11-Year Data Set. Environ. Sci. Technol. 48, 4732-4738. doi: 10.1021/es4053076

Lima, A. R. A., Barletta, M., and Costa, M. F. (2015). Seasonal distribution and interactions between plankton and microplastics in a tropical estuary. Estuar. Coast. Shelf Sci. 165, 213-225. doi: 10.1016/j.ecss.2015.05.018

Magini, C., Harari, J., Moledo, D., and Abessa, D. S. (2007). Circulação Recente de Sedimentos Costeiros nas Praias de Santos Durante Eventos de Tempestades?: Dados Para a Gestão de Impactos Físicos Costeiros. Araçatuba: UNESP, 349-355.

Moreira, F. T., Balthazar-silva, D., Barbosa, L., and Turra, A. (2016a). Revealing accumulation zones of plastic pellets in sandy beaches. Environ. Pollut. 218, 313-321. doi: 10.1016/j.envpol.2016.07.006

Moreira, F. T., Prantoni, A. L., Martini, B., de Abreu, M. A., Stoiev, S. B., and Turra, A. (2016b). Small-scale temporal and spatial variability in the abundance of plastic pellets on sandy beaches: methodological considerations for estimating the input of microplastics. Mar. Pollut. Bull. 102, 114-121. doi: 10.1016/j. marpolbul.2015.11.051

Nelms, S. E., Duncan, E. M., Broderick, A. C., Galloway, T. S., Godfrey, M. H., Hamann, M., et al. (2015). Plastic and marine turtles: a review and call for research. J. Mar. Sci. 73, 165-181. doi: 10.1093/icesjms/fsv165

Pereira, C. (2014). Microplásticos no Ambiente Marinho: Mapeamento de Fontes e Identificação de Mecanismos de Gestão Para Minimização de Perda de Pellets Plásticos. Brazil: University of São Paulo.

Quinn, G. P., and Keough, M. J. (2002). Experimental Design and Data Analysis for Biologists. Cambridge, MA: Cambridge University Press.

Rech, S., Macaya-Caquilpán, V., Pantoja, J. F., Rivadeneira, M. M., Jofre Madariaga, D., and Thiel, M. (2014). Rivers as a source of marine litter-a study from the SE Pacific. Mar. Pollut. Bull. 82, 66-75. doi: 10.1016/j.marpolbul.2014.03.019

Rochman, C. M., Browne, M. A., Halpern, B. S., Hentschel, B. T., Hoh, E., Karapanagioti, H. K., et al. (2013). Policy: classify plastic waste as hazardous. Nature 494, 169-171. doi: 10.1038/494169a

Ryan, P. G., Perold, V., Osborne, A., and Moloney, C. L. (2018). Consistent patterns of debris on South African beaches indicate that industrial pellets and other mesoplastic items mostly derive from local sources. Environ. Pollu. 238, 1008-1016. doi: 10.1016/j.envpol.2018.02.017 
Sadri, S. S., and Thompson, R. C. (2014). On the quantity and composition of floating plastic debris entering and leaving the Tamar Estuary. Southwest England. Mar. Pollut. Bull. 81, 55-60. doi: 10.1016/j.marpolbul.2014.02.020

Taniguchi, S., Colabuono, F. I., Dias, P. S., Oliveira, R., Fisner, M., Turra, A., et al. (2016). Spatial variability in persistent organic pollutants and polycyclic aromatic hydrocarbons found in beach-stranded pellets along the coast of the state of São Paulo, southeastern Brazil. Mar. Pollut. Bull. 106, 87-94. doi: 10. 1016/j.marpolbul.2016.03.024

Thompson, R. C. (2015). "Microplastics in the marine environment: sources, consequences and solutions," in Marine Anthropogenic Litter, eds M. Bergmann, L. Gutow, and M. Klages, (Berlin: Springer International Publishing), 185-200. doi: 10.1007/978-3-319-16510-3_7

Turner, A., and Holmes, L. (2011). Occurrence, distribution and characteristics of beached plastic production pellets on the island of Malta (central Mediterranean). Mar. Pollut. Bull. 62, 377-381. doi: 10.1016/j.marpolbul.2010. 09.027

Turra, A., Manzano, A. B., Dias, R. J. S., Mahiques, M. M., Barbosa, L., Balthazar-Silva, D., et al. (2014). Three-dimensional distribution of plastic pellets in sandy beaches: shifting paradigms. Sci. Rep. 4:4435. doi: 10.1038/srep0 4435

Underwood, A. J. (1997). Experiments in Ecology: Their Logical Design and Interpretation Using Analysis of Variance. Cambridge, MA: Cambridge University Press.

UNEP (2014). Une P Year Boo K. Nairobi: United Nations Environmental Programme.
Vermeiren, P., Muñcz, C. C., and Ikejima, K. (2016). Sources and sinks of plastic debris in estuaries: a conceptual model integrating biological, physical and chemical distribution mechanisms. Mar. Pollut. Bull. 113, 7-16. doi: 10.1016/ j.marpolbul.2016.10.002

Williams, A. T., Randerson, P., Allen, C., and Cooper, J. A. G. (2017). Beach litter sourcing: a trawl along the Northern Ireland coastline. Mar. Pollut. Bull. 122, 47-64. doi: 10.1016/j.marpolbul.2017.05.066

Williams, A. T., Randerson, P., Di Giacomo, C., Anfuso, G., Macias, A., and Perales, J. A. (2016). Distribution of beach litter along the coastline of Cádiz. Spain. Mar. Pollut. Bull. 107, 77-87. doi: 10.1016/j.marpolbul.2016.04.015

Yonkos, L. T., Friedel, E. A., Perez-Reyes, A. C., Ghosal, S., and Arthur, C. D. (2014). Microplastics in four estuarine rivers in the chesapeake bay. U.S.A. Environ. Sci. Technol. 48, 14195-14202. doi: 10.1021/es5036317

Conflict of Interest: The authors declare that the research was conducted in the absence of any commercial or financial relationships that could be construed as a potential conflict of interest.

Copyright (c) 2020 Balthazar-Silva, Turra, Moreira, Camargo, Oliveira, Barbosa and Gorman. This is an open-access article distributed under the terms of the Creative Commons Attribution License (CC BY). The use, distribution or reproduction in other forums is permitted, provided the original author(s) and the copyright owner(s) are credited and that the original publication in this journal is cited, in accordance with accepted academic practice. No use, distribution or reproduction is permitted which does not comply with these terms. 